\title{
CHALLENGES OF A 100\% RENEWABLE ENERGY SUPPLY IN THE JAVA-BALI GRID
}

\author{
Matthias Günther ${ }^{1 *}$ \\ ${ }^{1}$ Swiss-German University, The Prominence Tower, Jalan Jalur Sutera Barat Kav 15, Alam Sutera, \\ Tangerang 15143, Banten, Indonesia
}

(Received: December 2017 / Revised: December 2017 / Accepted: February 2018)

\begin{abstract}
Renewable energy resources are increasingly being used to cover the demand in the electricity grids in many countries. A question that is currently for most grids rather theoretical, although interesting in introducing a long-term perspective, pertains to what an energy supply from exclusively renewable energy resources could look like. This question has to be answered individually for each grid. The objective of the present paper is to scrutinize the specific challenges that a 100\% renewable energy scenario brings for the Java-Bali grid. This objective is achieved by designing power generation time series such that they match a given load time series. An important challenge for a $100 \%$ renewable energy supply is the very high dependency on solar energy, which generates an enormous primary power generation fluctuation on both a daily and an annual timescale. In particular the seasonal fluctuations come along with high storage demand, which is the greatest challenge involved in a 100\% renewable energy supply. There are strategies that may be used to considerably reduce the storage demand: the installed photovoltaic (PV) capacity can be increased, bioenergy can be used for seasonal balancing, and special long-term storage can be added. These options are considered in the present paper.
\end{abstract}

Keywords: $\quad$ Energy Scenario; Java-Bali grid; Storage; Time series analysis

\section{INTRODUCTION}

The present paper presents a 100\% renewable energy scenario (100\% RE scenario) for the JavaBali grid (JB grid) and discusses the main challenges of such a scenario. This involves simulating a future energy supply in which the electricity consumed in the JB grid is completely generated from renewable resources, and scrutinizing the most critical issues.

A $100 \%$ RE scenario for the JB grid is highly counterfactual given that the real share of electricity from renewable resources in this grid is below $10 \%$ at present. However, a scenario obviously does not have the task of representing the real state of affairs. The scenario refers to the year 2050. This does not mean that we assume that an exclusively renewable energy supply would be realized in that year. A scenario is neither a prediction. Nor is a scenario a development plan. In fact, Indonesia has set the targets of delivering $23 \%$ of the needed end energy (over all sectors) from renewable sources by the year 2025, and 25\% of the electric energy (Irena, 2017). Instead, a scenario has the objective of scrutinizing the consequences, benefits, and challenges of taking a specific development path, without necessarily making statements about the probability or improbability that the respective development path will be chosen. The designing of scenarios is a useful strategy for decision makers who need to conceptualize the implications of their

\footnotetext{
${ }^{*}$ Corresponding author's email: mguenther.germany@gmail.com, Tel: +62-812-85006717, Fax: +62-21-29779598
} Permalink/DOI: https://dx.doi.org/10.14716/ijtech.v9i2.1027 
decisions.

The JB grid represents a particularly difficult case for a $100 \%$ RE scenario. Not only is it by far the largest grid in Indonesia, supplying $76 \%$ of the national electricity consumption, but it also covers a very densely populated area, with nearly 1000 people per square kilometer. The latter is a particular problem for a renewable resource-based system, given that the usage of some of these resources requires the occupancy of quite large areas. This holds true especially for the usage of solar energy, which is the main resource used in the present scenario; large areas would be covered with photovoltaic (PV) modules. A challenge related to the massive usage of PV electricity is the demand for large storage capacities. We consider this to be the central challenge of a 100\% RE scenario for the JB grid and concentrate on the storage issue in the present paper.

The modeling of a possible future supply from renewable sources alone has been carried out for many energy supply systems in the world (Umweltbundesamt, 2010; Henning \& Palzer, 2012; Hinrich-Rahlwes, 2013). Such scenarios encourage a long-term perspective, suggesting how grid structures, from a present point of view, could or should develop in the future. However, such a scenario for the JB grid has not been discussed before. We do not know of any comparable projects and so consider the tackling of this topic as our original contribution. Scenarios like those discussed in this paper are an important tool for policy makers who must scrutinize the consequences of promoting one development path or another.

\section{METHODOLOGY}

The calculations are carried out on the basis of time series. A complete year is modeled with load and generation time series in an hourly resolution. The load time series is given for the year 2050 and it is based on the real load curve of the JB grid in the past and on a consumption model for the next decades. The generation modeling is undertaken in accordance with the load curve. The decisive boundary condition is that the electricity generation covers the load at any time.

Each generation type contributes to the coverage according to its proper logic. For instance, solar electricity is generated whenever solar radiation is provided. Solar electricity generation is modeled on the basis of meteorological data for the grid area, which in the present study are acquired from the commercial data supplier Meteonorm (www.meteonorm.com). Seventeen locations all over the grid area are selected on which the PV power plants are placed. Unlike PV power, hydropower and bioenergy are more flexible in their generation profile and hence follow another logic. Geothermal power plants, finally, are operated as base-load power plants. The general generation logic in the power supply system is hence as follows: Geothermal power reduces the given load through a constant power contribution that is determined by the installed geothermal power plant capacity (assuming that the installed power plant capacity, rather than the geothermal heat flow, is the limiting factor in the power generation). Solar energy is used whenever solar radiation is provided. When solar power exceeds the remaining load (discounting the given geothermal power), it is stored or dumped (if storage capacities are insufficient). The available hydropower and biopower, limited by the given river runoff and the given amount of considered agricultural waste, are allocated on demand (within certain flexibility limits). Storage systems deliver the electricity when the primary generation of the relevant power plants does not meet the load.

The supply scenario provides only a lower bound estimation of the required capacities: First, transmission and distribution losses, which in a grid can amount to up to ten percent of the generated electricity, are not considered. Second, the supply model does not take into account meteorological variances, but is based on a specific meteorological model year. A real system must allow for meteorological variances. Third, in an analog way, the generation model does not take into account possible load pattern variances. Fourth, the whole modeling process is 
performed from a bird's eye view, which does not reflect the perspective of a real system operator. In fact, a real system operator can only make more or less reliable assumptions about the future, based on a known past; he or she cannot know with certainty the load and generation conditions throughout a whole year. The adoption of the bird's eye view may be less critical for load modeling because the system is extensive, with a large number of consumers, which makes the load more easily predictable; however, it is more problematic for supply modeling due to a given uncertainty concerning weather conditions. This uncertainty influences the allocation of the available energy resources under real operation conditions, and it increases the demand for safety margins.

\section{RESULTS AND DISCUSSION}

\subsection{Load Scenario and Electricity Mix}

The load scenario is based on assumptions about population growth, economic development, and energy elasticity with respect to economic growth. We assume a population growth with gradually decreasing growth rates (according to the UN projection, Indonesia's population peak will be reached shortly after the year 2050, the target year of our scenario), as well as smooth economic development with a per-capita productivity that exhibits likewise decreasing, but always positive, growth rates. We take into account some probable energy efficiency increases, so that the energy elasticity with respect to economic growth, which is still greater than 1 (i.e., a one-percent increase in GDP comes along with an increase in electricity consumption of more than one percent), will decrease and fall below 1. The assumptions render a consumption of 640 TWh for the target year 2050, which is equivalent to an annual consumption of $3700 \mathrm{kWh}$ per capita. This annual per-capita consumption is equivalent to the current per-capita consumption of Malaysia and is considerably lower than, for example, those of Germany $(6,700 \mathrm{kWh})$ or South Korea $(9,300 \mathrm{kWh})$. The corresponding load curve is derived from that of the year 2014 (data courtesy of PT PLN), by scaling it up such that the modeled annual consumption of $640 \mathrm{TWh}$ is reached. We do not analyze consumption modeling in more detail here as the present study concentrates instead on supply modeling.

Four energy sources are taken into account in order to satisfy the modeled demand: solar radiation, geothermal energy, biomass, and river runoff. For geothermal power and hydropower the existing power plants are considered as well as the projected plants contained in the PLN business plans (PLN, 2017) and some additional capacity due to the fact that the considered business plans extend only until the year 2025, while the target year of the scenario is 2050 . Capacity factors are assigned to the assumed installed capacities so that respective annual energy yields can be determined. For the geothermal power plants a capacity factor of $85 \%$ is chosen. For the hydropower plants a limit of $35 \%$ is selected due to the seasonal rainfall fluctuations. Monthly energy amounts are allocated to the hydropower plants in accordance with seasonal river runoff patterns (extrapolated from measured data pertaining to the Citarum River in West Java; data courtesy of PT PLN). For bioenergy, no power plant capacity is specified, but an energy amount is assumed to be available annually. This amount is derived from a study on bioenergy from agricultural waste conducted by GIZ. The agricultural waste taken into account in this study comes from palm oil plantations, sugar cane plantations, and rice production (GIZ, 2014). Special bioenergy plantations are not considered; the high population density of Indonesia makes land use for bioenergy generation highly problematic.

The energy yield of geothermal power plants, hydropower plants, and biopower generators is hence defined. The difference between this yield and the consumption must be covered by solar power. Solar power is taken as practically unlimited. Solar electricity is harvested exclusively by using PV systems. 
Table 1 shows the energy supply from the different resources considered, and the installed capacity, if defined.

Table 1 Power plant mix and annual energy supply

\begin{tabular}{lcrr}
\hline \multicolumn{1}{c}{ Type of power plant } & $\begin{array}{c}\text { Installed capacity } \\
\text { (MW) }\end{array}$ & $\begin{array}{c}\text { Annual energy supply } \\
\text { (TWh) }\end{array}$ \\
\hline Geothermal power & 5,500 & 41 & $(6 \%)$ \\
Hydropower & 5,800 & 18 & $(3 \%)$ \\
Biopower & not determined & 7 & $(1 \%)$ \\
PV & open parameter & 574 & $(90 \%)$ \\
\hline
\end{tabular}

Wind power is not taken into account owing to the fact that the average wind speed in the grid area is fairly low compared to the wind speeds that are generally accepted as necessary for the commercial operation of wind turbines (Technical University of Denmark, 2017). Ocean energy is also neglected due to the unclear economic perspective of the respective technologies.

Solar power is generated using PV. In the present study, we consider only PV, and not solar thermal power plants, which are not an appropriate option for the grid area due to the relatively weak direct radiation conditions on the respective islands. As the generation of solar electricity with PV is dependent on the given solar radiation, the solar electricity generation fluctuates greatly and it is not possible for it to be delivered on demand. However, PV covers by far the largest share of the required electricity, resulting in a high demand for storage systems to match the power generation to the load.

There are currently pumped storages in construction or planning, with a capacity of approximately $20 \mathrm{GWh}$ and a charging/discharging power of approximately $4 \mathrm{GW}$ (PLN, 2017). These storages are far from sufficient to match the power generation to the load. We include, therefore, an additional storage system that is initially defined as a combination of further pumped storages and batteries. We distinguish, hence, between the following six system components: geothermal power plants, hydropower plants, biopower plants, PV power plants, pumped storages (of approximately $20 \mathrm{GWh}$, as aforementioned), and additional storage.

\subsection{Basic System}

The operational logic of the basic supply system (thus called because the other systems are derived from it) is as follows: Geothermal power is generated permanently at $85 \%$ of the installed capacity. Solar power is generated according to the radiation conditions covering as much as possible of the load not covered by the geothermal power plants. If there is excess solar power, as much as possible is stored in the storage systems. The pumped storage $(20 \mathrm{GWh})$ is charged every day (if sufficient excess solar energy is available, which is the case under any reasonable system dimensioning) and discharged in the evening/night during the respective peak load hours. The hydropower plants use the energy that is allocated to the months of a year for peak load shaving within the respective months. As such, we assume that the water storages in the hydropower plants are large enough to shift the electricity generation on a monthly timeframe, but are not sufficient to allow for a seasonal shift. The annually available bioenergy is used for further peak load shaving (with respect to the load that remains after supplying power from all the other generators). The additional storage system supplies the power needed to cover the remaining load.

The operational logic is represented in Figure 1, where the structure of the power supply in a oneweek period is shown. 


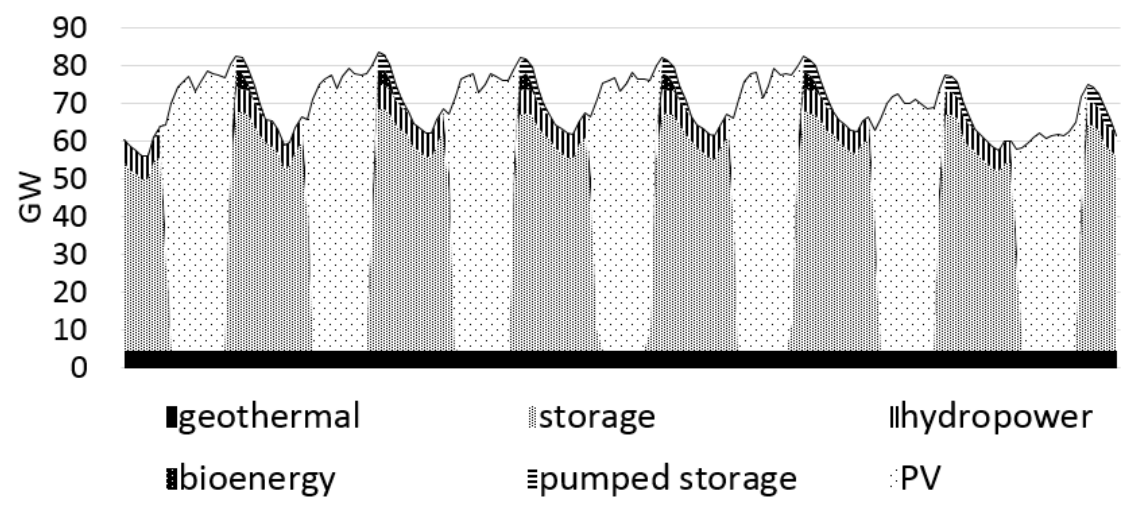

Figure 1 Energy supply during a one-week period according to the operational logic of the basic system

For the installed capacities there are two open parameters in the basic system: the installed PV capacity and the installed storage capacity. These two parameters depend on each other; the larger the installed PV capacity, the smaller the storage capacity, and vice versa (Figure 2). There is a system configuration for which the PV capacity is at its minimum at the cost of a large storage capacity, and a configuration for which the storage capacity is at its minimum at the cost of a large PV capacity. The minimum PV capacity is approximately $410 \mathrm{GW}$ (with a module area of approximately $2500 \mathrm{~km}^{2}$, which amounts to $1.9 \%$ of the land area; $2.3 \mathrm{~kW}$ or $14 \mathrm{~m}^{2}$ module area per capita), and the minimum storage capacity is approximately $950 \mathrm{GWh}(5.4 \mathrm{kWh}$ per capita). In order to obtain the minimum PV capacity, an enormous storage capacity of $16 \mathrm{TWh}(90 \mathrm{kWh}$ per capita) would be necessary. The location of the economically optimal system configuration depends on the costs of the installation and operation of both the PV power plants and the storage systems.

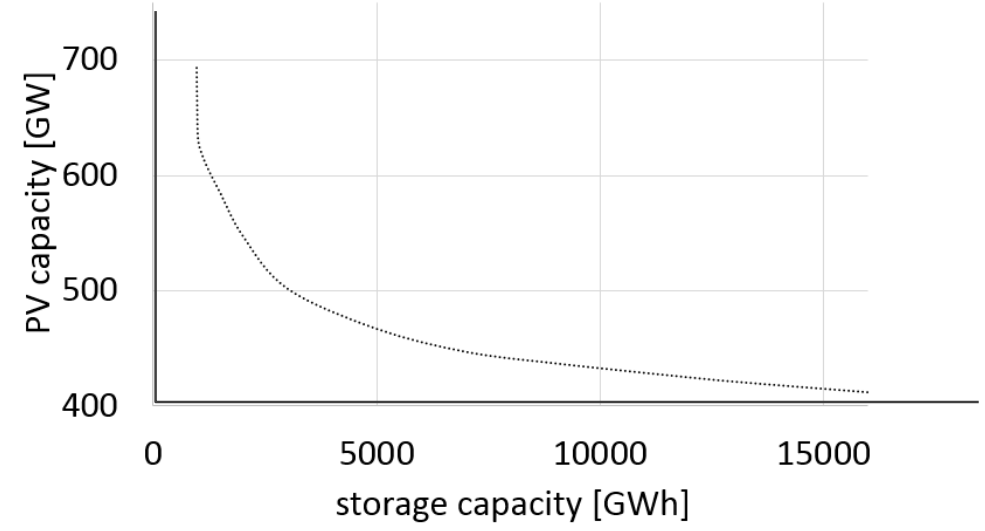

Figure 2 Storage capacity and PV capacity in the basic system

\subsection{The Main Challenges: High Dependency on Solar Energy and High Storage Demand} Both the large PV capacity and the large storage capacity required are significant challenges for a renewable energy-based power supply in the JB grid. The large PV capacity is not easy to allocate. A rough estimation shows that only a small share of the necessary PV can be located on buildings. The largest share must be located in other places. An obvious option is to use groundmounted systems. However, taking into account that land is very valuable in the densely populated and very fertile islands, it is not easy to allocate such a large amount of PV power plants. As little land area as possible should be used for electricity generation, which, from an ecological point of view, means that the creation of bioenergy plantations on these islands - and in Indonesia generally - is impossible. Therefore, offshore systems should be taken into 
consideration too. Offshore PV has not been widely utilized, but such systems may be better suited to and more worth considering for Indonesia than for most other places on Earth.

An even greater challenge than that of locating the large PV capacity, however, pertains to installing the necessary storage capacity. Pumped storages require certain geographical conditions and they also consume land. There are alternative pumped storage concepts, such as underground pumped storages, underwater pumped storages, and - especially relevant for the considered grid - seawater pumped storages, but their economic perspective is not yet clear. Battery storages are an option, but the huge amount of storage capacities required and the related costs still constitute an enormous challenge. However, this challenge may be alleviated if battery costs fall as steeply in the coming years as has been predicted by battery producers and market observers (McKinsey, 2017).

In order to overcome these fundamental challenges, the best strategy would be to shift the curve in Figure 2 downwards or leftwards, i.e. to enable less storage capacity to be needed at a given PV capacity, and less PV capacity to be needed at a given storage capacity. This can be achieved through modifications in the system operational logic or by adding further system components. In the following sections we will discuss two options.

\subsection{Reducing PV and Storage Capacities: Bioenergy for Seasonal Balancing}

The storage system is needed in order to balance the primary power generation fluctuations in two different frequency ranges: daily fluctuations and seasonal fluctuations. The required storage capacities are large, essentially owing to seasonal balancing, which is necessary because the solar power generation varies between dry and rainy season. The storage system has the task of shifting energy from the sunnier dry season to the cloudier rainy season (if the installed PV capacity is not too excessive), such that sufficient solar power is also generated in the rainy season. If the storage system is relieved from this task, the storage capacity can be reduced. One possible way in which to achieve this is by using the available bioenergy for seasonal balancing instead of peak load shaving. Bioenergy generally has the potential to be used for long-term balancing. The biomass itself can be stored for a certain amount of time, and the secondary energy carrier (if existing), e.g. biogas, can be stored for a very long time. The operational logic in this alternative system is implemented in the model in the following way: Bioenergy is allocated to those days in which the difference between energy consumption and available solar energy is large. Such days tend to be cloudy weekdays in the rainy season.

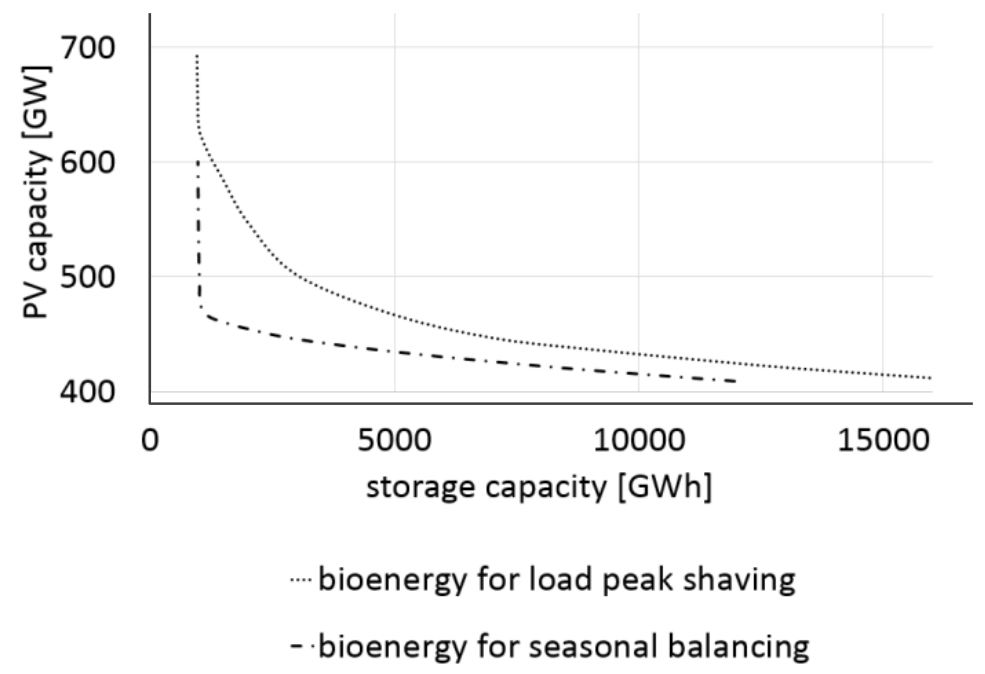

Figure 3 Storage capacity and PV capacity in the basic system and in the system using bioenergy for seasonal balancing 
The effect of this modified application of the available bioenergy is represented in Figure 3. The curve is shifted downwards, or leftwards. For any given PV capacity, the required storage capacity is lower than that of the basic system; similarly, for any given storage capacity, the required PV capacity is lower than that of the basic system. The limited amount of available bioenergy is not sufficient to completely balance the seasonal differences, but it can reduce them considerably and, hence, reduce the required storage capacity. For instance, at an installed PV capacity of $470 \mathrm{GW}$, the storage capacity drops from 5,000 GWh to just 1,000 GWh.

\subsection{Reducing PV and Storage Capacities: Adding a Long-term Storage}

Another way in which to shift the curve in Figure 2 downwards or leftwards, i.e. to reduce the demand for pumped storages and batteries at any given PV capacity, or to reduce the demand for $\mathrm{PV}$ at any given combined pumped storage and battery capacity, is through the integration of a special long-term storage into the system. The long-term storage can fulfill the task of seasonal balancing, while the pumped storages and batteries can fulfill the task of daily balancing. The distinction between short-term and long-term storage is useful in the following sense: Some storage types have high capacity costs, but low charging/discharging costs, while others have high charging/discharging costs, but low capacity costs. The first type is appropriate for shortterm storing. The high capacity costs can be tolerated more easily at a high frequency of charging/discharging cycles, i.e. with a high energy throughput through a given storage capacity in a given time span. Pumped storages and batteries are typical examples of this storage type. The second type is appropriate for long-term storing. The high costs of charging and discharging can be tolerated more easily at a low cycle frequency, i.e. with a low energy throughput through a given storage capacity in a given time span (Kemfert et al., 2016).

In this study, methane storage is used as a type of long-term storage. In the first step, excess power is used to generate hydrogen through the electrolysis of water. In the second step, the hydrogen is used to produce methane through the Sabatier process with the exothermic reaction: $\mathrm{CO}_{2}+4 \mathrm{H}_{2} \rightarrow \mathrm{CH}_{4}+2 \mathrm{H}_{2} \mathrm{O}$. The charging process is expensive due to the costly charging technology (electrolyzers and methanation units) and to large energy losses. The storage capacity, on the other hand, is cheap. In the present model, we do not limit the capacity of the long-term storage. However, due to the fact that the charging infrastructure implies high costs, the model considers both unlimited and limited charging capacities.

In the model, the long-term storage is subordinated to the pumped storages and the batteries; the long-term storage is only charged if the pumped storages and batteries cannot store all the excess energy, and is only discharged if the pumped storages and batteries cannot supply all the energy required. As such, the long-term storage is used only in situations of exceptional solar power excess and exceptional primary power deficit.

Figure 4 illustrates the effect of adding a long-term storage with and without charging power limitations. Charging power limitations are quantified as electrolyzer capacities. We assume that the capacity of the methanation units is sufficient to convert the produced hydrogen directly into methane, i.e. without the necessity to store the hydrogen. A sufficiently large dimensioning of the methanation units results in a more economic system overall, as the installation of smaller methanation capacities would mean that hydrogen storages would be required in addition to the methane storages. 


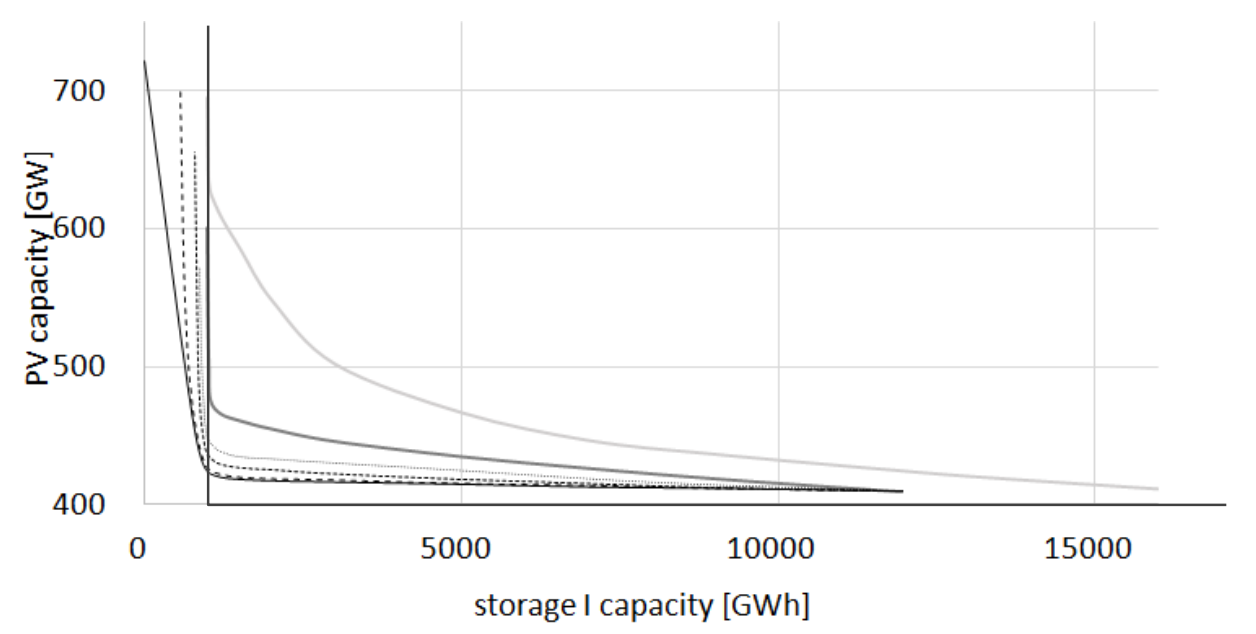

$$
\begin{array}{ll}
\text { - bioenergy for load peak shaving } & \text { - bioenergy for seasonal balancing } \\
\text { - unlimited electrolysis capacity } & \text {-- electrolysis } 100 \mathrm{GW} \\
\text {---electrolysis } 25 \mathrm{GW} & \text { - electrolysis } 10 \mathrm{GW}
\end{array}
$$

Figure 4 Combined pumped storage and battery capacity and PV capacity in the basic system, in the system using bioenergy for seasonal balancing, and in the system using additional long-term storage with different charging limitations (electrolyzer input power)

Even quite small charging powers for the long-term storage considerably reduce the amount of combined pumped storage and battery capacity required. If the long-term storage charging capacity is $10 \mathrm{GW}$, for instance, the required combined pumped storage and battery capacity is reduced by nearly 3,000 GWh (from 4,000 GWh in the system without long-term storage to 1,100 GWh in the system with long-term storage) at an installed PV capacity of $440 \mathrm{GW}$; meanwhile, the required PV capacity is reduced by $90 \mathrm{GW}$ (from $540 \mathrm{GW}$ in the system without long-term storage to $450 \mathrm{GW}$ in the system with long-term storage) at an installed combined pumped storage and battery capacity of $1,000 \mathrm{GWh}$.

Contrary to the alternative usage of the available bioenergy, as discussed in the previous section, the implementation of the long-term storage requires an additional investment. Whether the complementation of the pumped storages and batteries with a long-term storage is economically viable and how large the different storage systems should be depend on the costs of the respective components. A more specific economic evaluation of the different system designs is not the focus of the present text, but will be discussed in a subsequent paper. However, it may be predicted that a decrease in the cost of the battery system would reduce the need for relatively expensive electrolyzer and methanation infrastructure and for less efficient power-to-gas storing.

\section{CONCLUSION}

From the present point of view, a transformation of the electricity supply system on Java and Bali into a renewable energy-based one would come along with a massive use of PV power plants. Such a large PV capacity alone would pose a considerable challenge because the available roof area is small compared to the at least $2500 \mathrm{~km}^{2}$ module area required, while the land use for solar power generation should be kept as small as possible. In view of this difficulty, it is recommended that offshore PV should be considered as an option. There are only very few PV offshore systems in the world at present, and none in the open sea. However, the densely populated islands of Java and Bali are locations that may be better suited to offshore systems than almost anywhere else on Earth. Research and development programs concerning offshore PV should, therefore, be put on the Indonesian research policy agenda. Many appropriate locations can be identified, especially on the northern shore of the islands, where the sea is quiet. 
The biggest challenge, however, pertains to the need for large storage capacities due to the high dependence on PV. Efforts should be made, therefore, to reduce the enormous dependency on solar energy. This can be achieved by, for instance, paying special attention to the promotion of hydropower and geothermal power. Ocean energy should also be considered. This was not taken into account in the scenario design of the present study because the economic perspective of ocean energy technologies is not yet clear. However, from a long-term perspective, it is recommended that Indonesia should participate in research and development activities focusing on ocean energy. The usage of ocean energy has the potential to contribute considerably in mitigating the problem of solar power fluctuations (Ernst \& Young et Associés, 2016). Whether this potential can be tapped depends on its cost development (Magagna \& Uihlein, 2015). Furthermore, the energetic usage of waste should be promoted. Adding municipal waste to the considered agricultural waste can increase the energy yield from waste, which, as argued above, can effectively reduce the need for storage systems.

As the storage capacity is essentially determined by the task of seasonal balancing, a long-term storage can relieve the pumped storages and batteries of this task. With the current cost structures, long-term storages, e.g. in the form of gas (methane) storages, should be considered. If the battery cost reductions that are predicted by some battery producers are achieved, special long-term storages may be dispensable. However, this must be confirmed in a further study.

Seawater pumped storages could be developed. Traditional pumped storages alone will not be able to satisfy the large storage demand. There may be a large world market for seawater pumped storages in the future, given that there are few suitable locations for traditional pumped storages in many places (Katsaprakakis et al., 2013).

Furthermore, it is worth noting that a grid extension to other islands could alleviate the challenges to a certain degree. A grid extension facilitates the integration of additional power plants into the grid, increases the capability of balancing generation fluctuations due to the weather variability, and can reduce the day-night contrast of solar electricity generation (if the grid extension broadens the geographical longitude range of the grid area). In this respect, the planned extension of the JB grid to Sumatra is a useful step, from a long-term perspective, to facilitate a large renewable energy share in the grid (HVDC Sumatra Java, 2016).

The JB grid presents particular challenges to a $100 \%$ RE scenario because the consumption in the grid is high, the islands are densely populated, and the dependency on the highly fluctuating solar power is significant. However, from a long-term perspective, the electricity supply system will approach a state in which it is based primarily on renewable resources, and the identified challenges will have to be overcome in one way or another. Some recommendations that suggest themselves, from the current perspective, have been outlined. These recommendations may have to be revised in the future in accordance with new technological or economic developments.

\section{ACKNOWLEDGEMENT}

I am grateful to Swiss-German University which supported this study with an internal research funding scheme. I would also like to thank PLN PT for making load data for the JB grid available as well as monthly river runoff data for the Citarum River in West Java. The latter data were useful in taking into account the seasonal variability of hydropower generation in the grid area.

\section{REFERENCES}

Ernst \& Young et Associés, 2016. Ocean Energies, Moving Towards Competitiveness: A Market Overview. Available Online at: https://arena.gov.au/assets/2016/10/1605SG797-EtudeSeanergy-lowres.pdf, Accessed on $12^{\text {th }}$ January 2018 
Gesellschaft für Internationale Zusammenarbeit (GIZ), 2014. Overview of the Waste-to-Energy Potential for Grid-connected Electricity Generation (Solid Biomass and Biogas) in Available online at: https://energypedia.info/images/5/57/Biomass_Potential_Indosian_Agroindustry.pdf, Accessed on $12^{\text {th }}$ January 2018

Henning, H.-M., Palzer, A., 2012. 100\% Erneuerbare Energien für Strom und Wärme in Deutschland. Fraunhofer ISE. Available online at: https://www.ise.fraunhofer.de/content/dam/ise/de/documents/publications/studies/studie100-erneuerbare-energien-fuer-strom-und-waerme-in-deutschland.pdf, Accessed on $14^{\text {th }}$ February 2018

Hinrich-Rahlwes, R. (ed.), 2013. Sustainable Energy Policies for Europe: Towards 100\% Renewable Energy. Boca Ratón: Taylor \& Francis

HVDC Sumatra Java, 2016. HVDC Sumatra Java. Available online at: http://hvdcsumatrajava.com/home, Accessed on $12^{\text {th }}$ January 2018

Irena, 2017. Renewable Energy Prospects Indonesia. Available online at: http://www.irena.org/DocumentDownloads/Publications/IRENA_REmap_Indonesia_report 2017.pdf, Accessed on $12^{\text {th }}$ January 2018

Katsaprakakis, D.A., Christakis, D.G., Stefanakis, I., Panos, P., Stefanakis, Nikos., 2013. Technical Details Regarding the Design, the Construction and the Operation of Seawater Pumped Storage Systems. Energy, Volume 55, pp. 619-630

Kemfert, C., Gerbaulet, C., von Hirschhausen, C., 2016. Stromnetze und Speichertechnologien für die Energiewende: Eine Analyse mit Bezug zur Diskussion des EEG 2016. DIW Berlin: Politikberatung kompakt, No. 112, ISBN 978-3-946417-02-6, Available online at: https://www.econstor.eu/handle/10419/142790, Accessed on $12^{\text {th }}$ January 2018

Magagna, D., Uihlein, A., 2015. JRC Ocean Energy Status Report. Technology, Market and Economic Aspects of Ocean Energy in Europe. Available online at: https://setis.ec.europa.eu/sites/default/files/reports/2014-JRC-Ocean-Energy-StatusReport.pdf, Accessed on $14^{\text {th }}$ February 2018

McKinsey, 2017. Electrifying Insights: How Automakers Can Drive Electrified Vehicle Sales and Profitability. Available online at: http://www.mckinsey.com/industries/automotive-andassembly/our-insights/electrifying-insights-how-automakers-can-drive-electrified-vehiclesales-and-profitability, Accessed on $12^{\text {th }}$ January 2018

PLN, 2017. Electricity Supply Business Plan of State Electricity Company (PT PLN Persero), Year 2013-2022, 2015-2024, 2016-2025. Available online at: http://www.djk.esdm.go.id/index.php/rencana-ketenagalistrikan/ruptl-pln, Accessed on $12^{\text {th }}$ January 2018

Technical University of Denmark. Department of Wind Energy, 2017. Global Wind Atlas. Available online at: http://globalwindatlas.com/index.html, Accessed on $12^{\text {th }}$ January 2018

Umweltbundesamt, 2010. Energieziel 2050: 100\% Strom aus erneuerbaren Quellen. Umweltbundesamt. Available online at: https://www.umweltbundesamt.de/presse/pressemitteilungen/energieziel-2050-100prozent-strom-aus-erneuerbaren, Accessed on $14^{\text {th }}$ February 2018 